Historic, archived document

Do not assume content reflects current scientific knowledge, policies, or practices. 



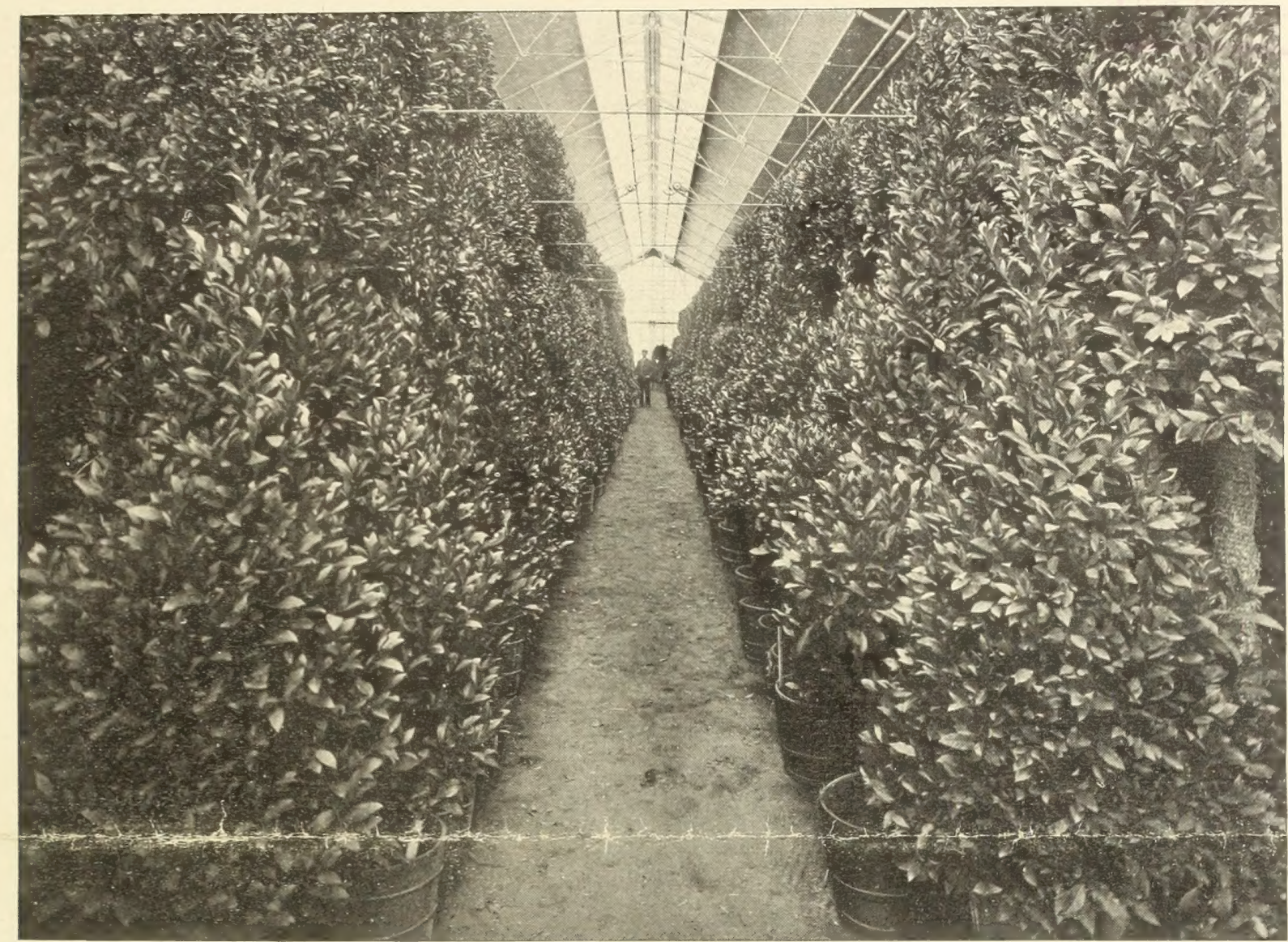

The above illustration shows Bay Trees now in stock at our new Riverview Nursery ready for immediate delivery

\section{Dreer's Special Import Offer OF}

Bay Trees and Araucarias

for the Spring of 1912

\section{HENRY A. DREER}

714 Chestnut Street

Philadelphia, Pa. 


\section{Special Import Prices on Bay Trees and Araucarias}

For several years we have made a special feature of booking advance orders for Spring delivery for Bay Trees and Araucarias, which has met with such encouragement from the trade throughout the country that we have continued this special arrangement with the most extensive Belgian grower of this class of plants and we herewith again submit prices at which we can accept advance orders for Spring imports, delivery to be made at any time between April 15th and May 15 th, but orders to secure these special import prices must reach us not later than March 25th, or, if possible, earlier, so that the trees may be reserved.

These import prices, including packing and delivery F. O. B. Philadelphia or New York, are much lower than our regular list price, and we offer not only an exceptionally full line of sizes, but also some comparatively new shapes not generally offered.

Do not overlook the fact that these prices are only for advance orders which must reach us before March 25th, 1912.

\section{Standard Bays with Square Heads}

This is a new form in Bays, stems 45 to 48 inches high, the square heads being 40 inches in diameter. These are growing in square tubs to conform to the shape of the crowns. $\$ 25.00$ each.

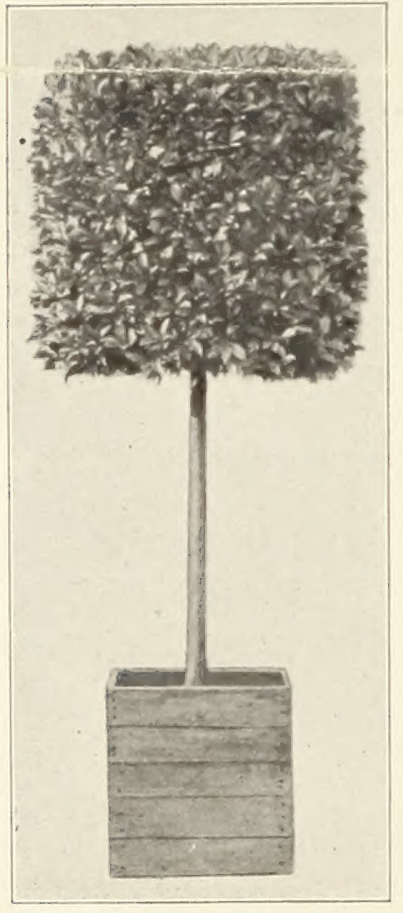

Standard Bay with Square Head

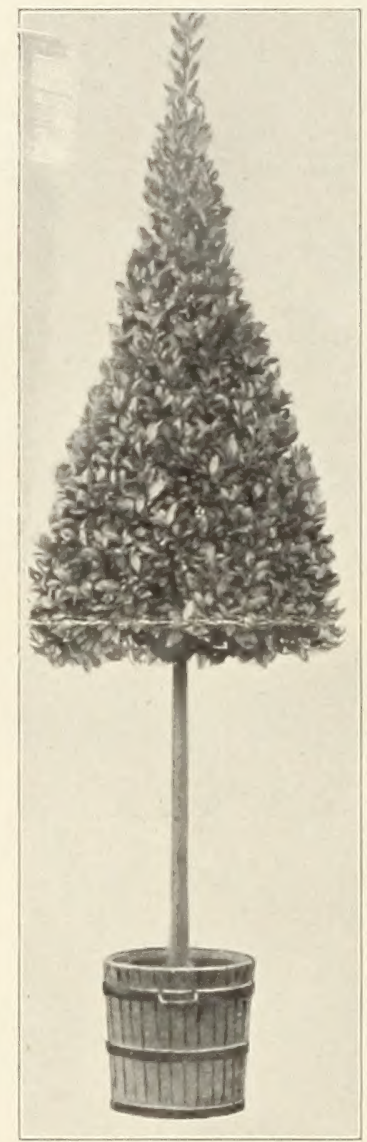

Imperial Pyramid-Shaped Bay

\section{Imperial Pyramid-Shaped Bays}

These are pyramid-shaped crowns grown on stems in the same way as the regular standards. They make very unique specimens.

$\begin{array}{rrrr}\text { Height of Stem } & \text { Height of Pyramid } & \text { Diameter at Base } & \text { Price each } \\ 40 \text { to } 45 \mathrm{in} . & 80 \mathrm{in} & 36 \mathrm{in} . & \$ 30.00 \\ 40 \text { to } 45 \mathrm{in} . & 40 \mathrm{in} . & 24 \mathrm{in} . & 10.00 \\ 24 \mathrm{in} & 80 \mathrm{in} & 26 \mathrm{in} . & 12.50 \\ 24 \mathrm{in} . & 50 \mathrm{in} . & 24 \mathrm{in} . & 7.00\end{array}$

\section{Column-Shaped Bays}

These are pyramids with rounded tops - not being grown to a sharp point as in the ordinary form; fine plants ; 80 inches high, 30 inches in diameter at base. Price \$25.00 each.

\section{Specimen Pyramid-Shaped Bays}

These are elegant specimens about fifty years old, standing from 13 to 14 feet high, and from $51 / 2$ to 6 feet in diameter at the base. $\$ 100.00$ each. 


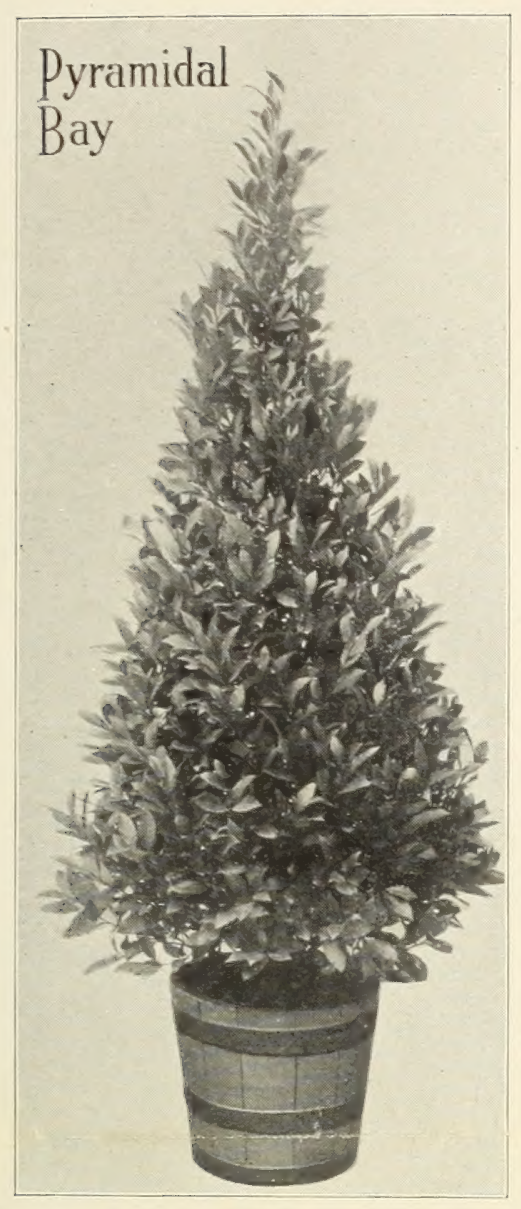

\section{Pyramid-Shaped Bays}

\begin{tabular}{|c|c|c|}
\hline Height & $\begin{array}{l}\text { Diameter } \\
\text { at Base }\end{array}$ & Price each \\
\hline 40 to 45 in. & 14 to 16 in. & $\$ 3,50$ \\
\hline 45 to 48 in. & 16 to $18 \mathrm{in}$. & 4.50 \\
\hline 50 to 54 in. & 18 to $20 \mathrm{in}$. & 5,00 \\
\hline 55 to $\epsilon 0$ in. & 22 to 24 in. & 6.00 \\
\hline 60 to 70 in. & 24 to 26 in. & 7.00 \\
\hline 70 to 80 in. & 28 to 30 in. & 9.50 \\
\hline 80 to 90 in. & 30 to 36 in. & 10.50 \\
\hline 90 to 100 in. & .36 to $40 \mathrm{in}$. & 12.50 \\
\hline $110^{-}$ & 42 to 45 in. & 15.00 \\
\hline 120 & 48 to $50 \mathrm{in}$. & 20.00 \\
\hline 125 & 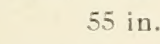 & 22. \\
\hline
\end{tabular}

\section{Dwarf Standard or Tree-Shaped Bays}

These are splendid dense trees with short stems selected to suit the buyer. Stems, 16, 18, 20, 22, 24, 26 or 30 inches high, and with crowns of the following diameter: Each Diam. of Crowns, 18 inches, $\$ 3.00$ " " 22 to 24 in. 4.00 Imperial Standard Tree-Shaped Bays

These are trees with exceptionally high stems, being from 70 to 80 inches high; crowns 30 inches in diameter, at $\$ 12.50$ each.

\section{Specimen Standard}

or Tree-Shaped Bays More than 100 years old]

Splendid specimens in strong solid tubs with stems $3,31 / 2,4,41 / 2$ and 5 feet high, and fine bushy crowns, from 9 to 10 feet in diameter, and from 8 to 9 feet in depth. $\$ 175.00$ each.

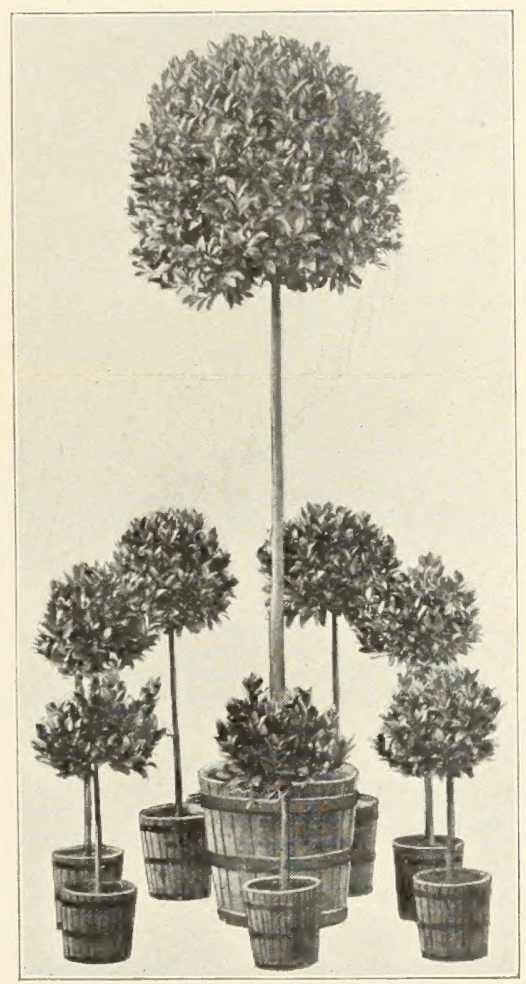

Imperial Standard and Dwarf Standard Bays

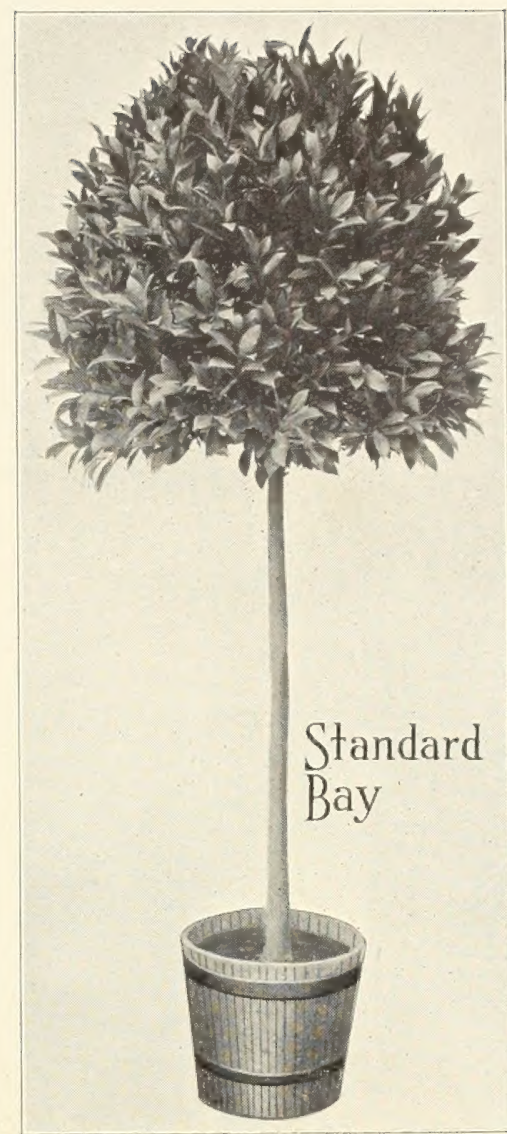

Standard or Tree-Shaped Bays

Height of Stems 40 to 48 inches Diameter of Crowns 20 to 22 inches

24 to 26 "،

28 to 30 ".

30 to 32

32 to 34

36 to 38 "

40 "

42
44 6

46 "6

48
50

55 " 6

60 6 6
Price each $\$ 3.50$ 4.50 6.00 7.00 8.00 9.50 10.50 12.00 12.50 15.00 17.50 20.00 25.00 30.00 35.00

\section{Bay Trees for Immediate Delivery}

For immediate delivery we are carrying in stock at our Riverview Nursery the sizes listed below in stock of prime condition

\section{Standard or Tree-Shaped}

We offer a recent importation of exceptional good value. Stems about 24 in. hich, crowns, 15 in. diam $\$ 2.00$

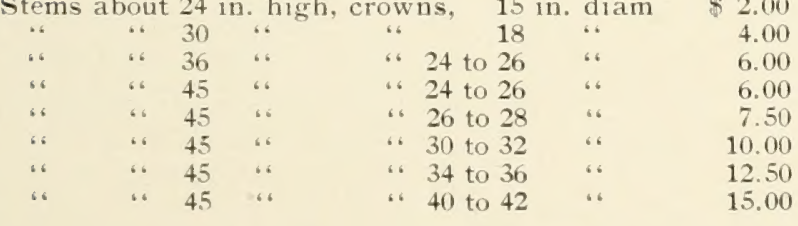

\section{Pyramidal-Shaped}

\begin{tabular}{|c|c|c|c|c|}
\hline & \multicolumn{3}{|c|}{3 feet high $\quad 16$ inches diameter at base } & \multirow{2}{*}{$\$ \begin{array}{l}\text { Each } \\
2.50 \\
6.00\end{array}$} \\
\hline feet high & \multirow{2}{*}{\multicolumn{3}{|c|}{24 to 26 inches $\quad$.. }} & \\
\hline $\begin{array}{lll}41 / 2 & \cdots\end{array}$ & & & & \multirow{2}{*}{$\begin{array}{r}7.50 \\
10.00\end{array}$} \\
\hline \multirow{3}{*}{$\begin{array}{l}\text {. } \\
6 \\
6\end{array}$} & 30 inches & “. & "6 & \\
\hline & 32 to 34 inches & “ & “ & $\begin{array}{l}10.00 \\
12.50\end{array}$ \\
\hline & 38 to 40 inches & ، & ، & 15.00 \\
\hline
\end{tabular}




\section{Special Import Prices}

\section{On Araucaria Excelsa, Glauca and Compacta For Early Spring Delivery}

We again call your attention to the special prices on Araucarias at which we are in position to accept import orders, delivery of which will be made during the latter part of April.

Many of our customers took advantage of similar import offers the past three years, and, as far as we know, the stock gave universal satisfaction, and having again made special arrangements with the most extensive Belgian growers, we believe that we are in position to give as good, if not better service than in past years.

You will find this profitable stock to handle. It will grow into value during the summer months at comparatively little cost for labor, with a positive and profitable market for it during the holidays.

Orders at these prices must reach us before March 25 th and will be filled during the latter part of April.

In ordering please refer to Circular No. 112.

\section{Araucaria Excelsa}

\begin{tabular}{|c|c|c|c|}
\hline \multicolumn{2}{|c|}{ Strong rooted top-cuttings, imported in $2 \frac{1}{2}$ and } & S 20.00 & 100 \\
\hline Strong plants & 2 tiers & 30.00 & . \\
\hline Strong plants & 3 tiers & 45.00 & . \\
\hline Strong plants & 3 to 4 tiers & 60.00 & “ \\
\hline Strong plants & 4 tiers & 75.00 & .. \\
\hline Strong plants & 4 to 5 tiers & 100.00 & " \\
\hline
\end{tabular}

\section{Araucaria Excelsa Glauca}

\begin{tabular}{|c|c|c|}
\hline Strong plants & 2 tiers & $\$ 45.00$ per 100 \\
\hline Strong plants & 3 tiers & 60.00 \\
\hline Strong plants & 3 to 4 tiers & 90.00 \\
\hline
\end{tabular}

Araucaria Robusta Compacta

$\begin{array}{lrr}\text { Heavy plants } & 2 \text { tiers } & \$ 85.00 \text { per } 100 \\ \text { Heavy plants } & 3 \text { tiers } & 100.00 \\ \text { Heavy plants } & 3 \text { to } 4 \text { tiers } & 125.00\end{array}$

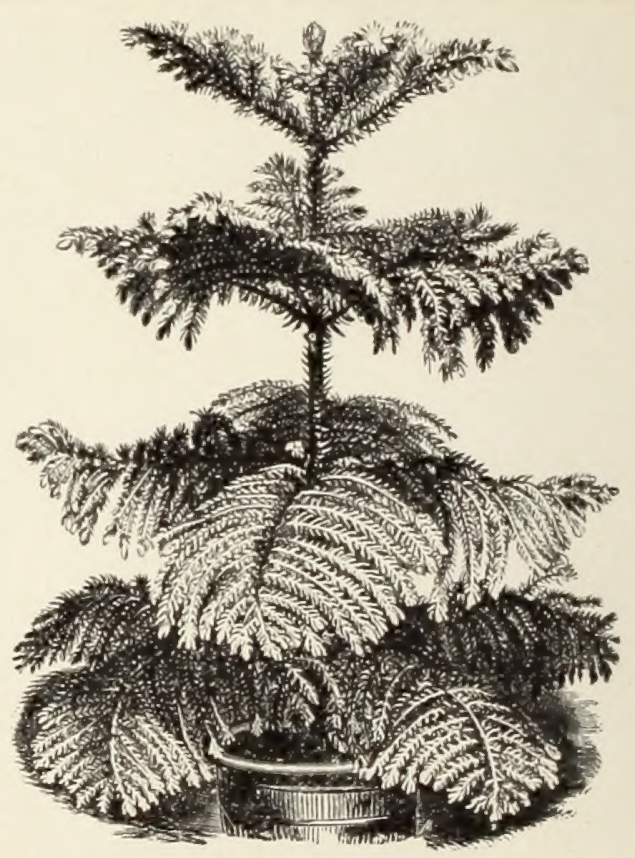

\section{HENRY A. DREER}

